\title{
ANALISIS TATA KELOLA TEKNOLOGI INFORMASI PADA LAYANAN INFRASTRUKTUR JARINGAN RSUD PROVINSI NTB MENGGUNAKAN COBIT 4.1
}

\author{
(IT Governance Analysis on RSUD Provinsi NTB Network Infrastructure Services \\ using COBIT 4.1)
}

Indri Rahmawati Yunus, Nadiyasari Agitha*, Sri Endang Anjarwani

Dept Informatics Engineering, Mataram University

Jl. Majapahit 62, Mataram, Lombok NTB, INDONESIA

Email: indryunus@gmail.com,nadiya@unram.ac.id, endang@unram.ac.id

\begin{abstract}
By utilizing IT network infrastructure services optimally, the use of information systems and other IT activities in RSUD Provinsi NTB will run smoothly. However there are some problems such as devices acquisition, maintenance and network infrastructure security that must be overcome to achieve maximally services in accordance with the vision and mission. Based on these problems, IT Governance is used as a matrix and guide to improve IT network infrastructure. This research uses COBIT 4.1 framework and maturity level as a measure of current conditions and expected conditions in RSUD Provinsi NTB. This observation results that the current maturity level is 3 and is expected yang diharapkan 5. We also propose some recommendations for improvements that are expected to overcome the problem that occurs and make improvements to existing IT network infrastructure service.
\end{abstract}

Keywords: IT Governance, Network Infrastructure, COBIT 4.1, Maturity Level, Recommendations for Improvements.

*Penulis korespondensi

\section{Pendahuluan}

Kebutuhan akan sistem informasi saat ini sangatlah besar terhadap berbagai bidang pekerjaan yang memanfaatkan teknologi tersebut untuk mencapai tujuannya. Perusahaan, organisasi, eksekutif dan pihak manajemen harus memastikan adanya keselarasan antara visi, misi dan strategi bisnis dengan pemanfaatan teknologi informasi (TI). Menurut Surendro Tata Kelola TI adalah cara untuk melakukan penyempurnaan tata kelola perusahaan ataupun organisasi yang menggunakan TI sebagai sarana penunjang untuk mempertahankan dan memperluas strategi dan tujuan bisnis. Tata Kelola TI di dalam suatu perusahaan mencakup tentang kepemimpinan, struktur serta proses organisasi yang berkembang di dalamnya [1].

Rumah Sakit Umum Daerah Provinsi Nusa Tenggara Barat (RSUD Provinsi NTB) merupakan salah satu unit penyelenggara pelayanan kesehatan milik Pemerintah Daerah Provinsi NTB. Pemanfaatan teknologi informasi di RSUD Provinsi NTB tidak terlepas dari layanan infrastruktur jaringan TI. Layanan infrastruktur jaringan TI mempengaruhi keberlangsungan operasional di RSUD Provinsi NTB.
Layanan infrastruktur jaringan $\mathrm{TI}$ ini menjadi jantung utama dalam penyelenggaraan TI di RSUD Provinsi NTB, dimana segala macam hardware, software dan brainware adalah hal-hal yang sangat berkaitan satu sama yang lainnya. Tanpa adanya layanan infrastruktur jaringan TI maka seluruh kegiatan TI tidak akan tercapai, seperti penggunaan sistem informasi yang tidak akan bisa dilaksanakan tanpa adanya infrastruktur jaringan seperti PC, internet, router, kabel fiber optic, hub, switch, repeater, access point dan modem. Dari hasil observasi dan wawancara awal yang dilakukan di bagian Instalasi Sistem Informasi Rumah Sakit (SIRS) RSUD Provinsi NTB ada beberapa masalah pada pengadaan barang untuk infrastruktur jaringan $\mathrm{TI}$ yang harus disesuaikan dengan anggaran belanja di mana layanan infrastruktur jaringan TI diadakan secara bertahap sehingga perlu ditentukan parameterparameter untuk menentukan prioritas pengadaan barang, tidak adanya pemeliharaan hardware atau software secara berkala dan masih kurangnya keamanan jaringan seperti pernah terjadinya deface pada website milik RSUD Provinsi NTB. Berdasarkan beberapa masalah tersebut kami menyimpulkan bahwa layanan infrastruktur jaringan TI di RSUD Provinsi NTB belum maksimal. 
Menurut IT Governance Institute framework COBIT 4.1 dapat mengoptimalkan penggunaan TI [2]. Framework COBIT 4.1 memberikan panduan tentang membuat skema klasifikasi yang berisi tentang pendefinisian tingkat keamanan dan pengendalian perlindungan; membuat rencana untuk akuisisi infrastruktur teknologi; memastikan ketersediaan dan perlindungan terhadap sumber daya infrastruktur; pemeliharaan infrastruktur; dan uji kelayakan lingkungan juga diperlukan untuk memaksimalkan penggunaan TI. Dari penuturan masalah awal tentang pengadaan, perawatan dan keamanan maka diperlukan sebuah tata kelola berupa rekomendasirekomndasi dengan menggunakan framework COBIT 4.1 sebagai landasan untuk memperbaiki layanan infrastruktur jaringan TI.

\section{TINJAUAN PUStaKa dAN DASAR TEORI}

\subsection{Tinjauan Pustaka}

Langkah awal yang dilakukan pada penelitian Ansori dan Buliali [3] adalah menentukan fokus pembahasan atau control objectives dengan melakukan identifikasi awal. Penelitian ini menitik beratkan pada 4 IT Proses, yaitu DS3, DS8, dan DS13. Selanjutnya dilakukan pengukuran tingkat kematangan setiap proses yang telah dipilih. Dari hasil pengukuran tersebut didapatkan untuk kondisi saat ini IT proses DS3, DS4 dan DS8 berada pada tingkat kematangan 1. Untuk kondisi saat ini pada IT proses DS13 berada pada tingkat kematangan 2. Untuk kondisi yang diharapkan IT proses DS3 dan DS4 berada pada tingkat kematangan 3. Kemudian untuk kondisi yang diharapkan IT proses DS8 dan DS13 berada pada tingkat kematangan 4. Tahapan terakhir adalah menyusun sebuah rekomendasi panduan model tata kelola TI yang dapat diterapkan oleh RSUD Kabupaten Sidoarjo dalam menjamin ketersediaan layanan TI. Panduan ini disusun berdasarkan perencanan solusi perbaikan dengan melakukan pendefinisian tindakantindakan perbaikan, indikator pencapaian dan target kinerja.

Penelitian Santi [4] mengevaluasi tata kelola teknologi informasi yang menitik beratkan pada proses DS5 Ensure System Security. Tahap pertama adalah menentukan responden berdasarkan struktur $\mathrm{RACl}$ chart IT Proses DS5. Setelah menentukan responden kemudian melakukan proses wawancara dan penyebaran kuesioner sebagai upaya dalam mengumpulkan data dengan metode purposive sampling. Data hasil wawancara dan kuesioner selanjutnya akan diolah dan dianalisis sedemikian rupa kemudian akan menghasilkan nilai tingkat kematangan dari dua kondisi yakni kondisi saat ini dan kondisi yang diharapkan. Hasil penelitian ini menunjukan nilai tingkat kematangaan kondisi saat ini berada pada tingkat kematangan 2 dan nilai tingkat kematangan kondisi yang diharapkan berada pada tingkat kematangan 3. Hasil akhir dari penelitian ini didapatkan dengan menyusun rekomendasi perbaikan yang akan disesuaikan dengan 6 atribut kematangan framework COBIT 4.1. Rekomendasi perbaikan tersebut disusun secara bertahap, dimulai dari tingkat kematangan kondisi saat ini kemudian naik satu tingkat menuju tingkat kematangan selanjutnya sampai kepada nilai tingkat kematangan yang diharapkan.

Penelitian Alit, Pratiwi dan Idhom [5] melakukan analisis data hasil wawancara kemudian mengidentifikasi dan menyelaraskannya ke dalam tabel Business Goals, tabel IT Goals, tabel IT Process dan tabel Control Objectives. Hasil identifikasi tersebut menghasilkan 4 IT Goals, 10 IT Process dan 17 detailed Control Objectives. Walaupun hasil identifikasi menghasilkan 10 IT Process namun pada penelitian ini menitik beratkan pada 4 IT Process yakni PO3, PO7, Al3, dan AI5. Hasil dari penelitian ini menunjukkan adanya gap sebesar 1.5 dan tingkat kematangannya berada pada tingkat kematangan 3. Guna meningkatkan pengelolaan infrastruktur teknologi informasi maka disusun sebuah rekomendasi perbaikan sebagai tindak lanjut dari hasil penelitian ini.

Berdasarkan ketiga hasil penelitian yang telah dipaparkan maka dapat disimpulkan bahwa penting bagi perusahaan atau organisasi untuk menerapkan tata kelola TI salah satunya adalah rumah sakit untuk mendukung tercapainya tujuan bisnis perusahaan. TI yang handal tidak hanya terdiri dari software namun juga dibangun dengan infrastruktur berupa hardware, sehingga diperlukan tata kelola untuk infrastruktur tersebut. Pada penelitian yang dilakukan bertujuan untuk mengukur dan menganalisis kondisi saat ini dan kondisi yang diharapkan dari RSUD Provinsi NTB. Pengukuran dan analisis difokuskan pada IT proses PO2 dan IT proses AI3, hasil pengukuran tersebut akan dianalisis sehingga dapat menghasilkan rekomendasi yang berkaitan dengan layanan infrastruktur jaringan. Pemilihan penggunaan framework COBIT 4.1 berdasarkan referensi-referensi yang didapatkan dan berdasarkan kebutuhan penelitian yang berfokus terhadap proses-proses TI. Framework COBIT 4.1 juga dikenal sebagai framework TI bukan framework bisnis organisasi. 


\subsection{Dasar Teori}

\subsubsection{Tata kelola teknologi informasi}

Pihak manajemen eksekutif dan dewan direksi dari suatu perusahaan atau organisasi memiliki tugas dan kewajiban untuk melakukan tata kelola TI. Dengan melakukan tata kelola TI pihak manajemen dapat memastikan dan menjamin bahwa visi, misi, rencana strategi dan tujuan bisnis perusahaan selaras dan dapat didukung dengan adanya penggunaan $\mathrm{TI}$ [2].

\subsubsection{COBIT}

Diperlukan sebuah kerangka kerja (framework) yang dapat digunakan untuk membantu pihak manajemen dalam menangani gap antara kebutuhan kontrol, masalah teknis dan resiko bisnis. COBIT adalah salah satu framework yang dapat mengkomunikasikan tingkat kontrol dengan pemangku kepentingan tersebut. COBIT menjadi sebuah framework tata kelola TI yang akan membantu pihak manajemen eksekutif dalam memahami dan mengatur resiko dan keuntungan bisnis yang terkait dengan TI [2].

\subsubsection{Balanced scorecard}

Balanced Scorecard menyajikan strategi-strategi yang dapat digunakan oleh pihak manajemen untuk menjabarkan visi, misi, rencana strategis dan tujuan bisnis perusahaan ke dalam 4 perspektif Balanced Scorecard. 4 perspektif yang dimaksud adalah perspektif keuangan, perspektif pelanggan, perspektif proses usaha dan perspektif pembelajaran dan pertumbuhan [6].

\subsubsection{Key performance indicator}

Setiap IT Proses memerlukan tolak ukur untuk menilai kinerja masing-masing IT proses tersebut dalam pemanfaatan $\mathrm{TI}$ di suatu perusahaan. KPI merupakan salah satu indikator utama dalam menilai kinerja IT Proses. Nilai yang digunakan dalam menentukan kinerja IT Proses berdasarkan KPI dinyatakan dalam bentuk persentase [7].

\subsubsection{RACl chart}

Untuk menentukan responden wawancara dan kuesioner pada penelitian ini menggunakan $\mathrm{RACl}$ chart. $\mathrm{RACl}$ chart akan menunjukkan peran dan fungsi manajemen eksekutif terhadap suatu aktifitas yang dibagi menjadi 4 peran. 4 peran tersebut adalah Responsible, Accountable, Consulted dan Informed. [8].

\subsubsection{Maturity models}

Maturity models digunakan untuk mengukur IT Proses berada pada tingkat kematangan tertentu. Tingkat kematangan tersebut dimulai dari level 0 nonexsistence sampai ke level 5 optimized. Dengan melakukan identifikasi terhadap tingkat kematangan tata kelola TI di suatu perusahaan maka peneliti dapat mengetahui keadaan aktual perusahaan tersebut pada kondisi saat ini dan mendefiniskan keadaan yang diharapkan pihak manajaemen sehingga dapat dilakukan perbaikan sampai pada tahap yang optimal [9].

\subsubsection{Jaringan komputer}

Jaringan komputer merupakan komunikasi antara beberapa komputer yang terhubung melalui sebuah media. Hubungan antar komputer ini kemudian dapat saling berbagi data dan informasi yang dapat disebarluaskan ke seluruh penjuru dunia [10]. Jaringan komputer terdiri dari beberapa komponen yakni hardware, software dan brainware.

\section{Metode Penelitian}

Pada penelitian ini dibuat diagram alir untuk menggambarkan urutan proses yang dilakukan dapat dilihat pada Gambar 1.

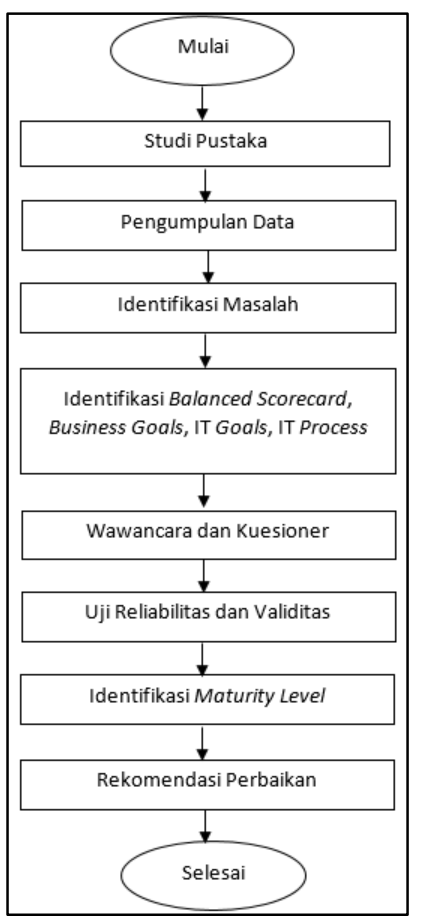

Gambar 1. Diagram alir penelitian

\subsection{Studi Pustaka}

Pada penelitian ini akan dilakukan serangkain proses tahapan penelitain. Proses pertama yang dilakukan adalah melakukan studi pustaka untuk mengumpulkan sejumlah data dan informasi penting yang akan dijadikan referensi seperti jurnal, skripsi, buku dan e-book. Referensi tersebut dijadikan acuan dalam pembuatan tinjauan pustaka dan dasar teori. 


\subsection{Pengumpulan Data}

Dalam melakukan suatu penelitian komponen utama yang harus dilakukan adalah melakukan pengumpulan data dan informasi. Pada tahapan awal penelitian ini akan dilakukan dua cara pengumpulan data yakni observasi dan wawancara. Data awal yang dikumpulkan pada proses ini akan digunakan untuk merumuskan permasalahan yang terjadi.

\subsection{Identifikasi Masalah}

Setelah melakukan tahap pengumpulan data, maka akan diidentifikasi masalah-masalah yang ada di RSUD Provinsi NTB. Terdapat beberapa masalah yang ditemukan pada proses pengumpulan data awal yang menunjukkan bahwa terdapat masalah mengenai pengadaan infrastruktur jaringan $\mathrm{Tl}$, tidak adanya perawatan terhadap infrastruktur jaringan $\mathrm{TI}$ secara berkala dan kurangnya keamanan jaringan. Masalahmasalah tersebut diselaraskan dengan visi dan misi dari RSUD Provinsi NTB untuk dijadikan fokus utama dalam pembuatan rekomendasi perbaikan selanjutnya.

\subsection{Identifikasi BSC, Business Goals, IT Goals, IT Process}

Pada tahap ini akan diidentifikasi visi dan misi RSUD Provinsi NTB. Visi dan misi RSUD Provinsi NTB ini akan dikelompokkan ke dalam empat perspektif BSC yaitu perspektif keuangan, perspektif pelanggan, perspektif proses usaha dan perspektif pembelajaran dan pertumbuhan.

Hasil pemetaan BSC yang telah dilakukan akan disesuaikan dengan 17 sasaran-sasaran strategis TI dan bisnis yang telah ditetapkan COBIT. Dari ke-empat perspektif BSC memiliki Business Goals yang berbedabeda.

Dilanjutkan dengan melakukan identifikasi terhadap 28 bidang kompetensi pengelolaan TI. Dari hasil mapping business goals yang didapat maka akan disesuaikan dengan 28 bidang kompetensi pengelolaan TI. Setiap Business Goals selalu memiliki satu atau lebih pasangan bidang kompetensi dari 28 bidang kompetensi IT Goals yang telah ditetapkan oleh COBIT.

Hasil dari tahap ini adalah penentuan dua IT Proses yang diambil sebagai fokus penelitian yakni IT Proses PO2 (Defined the Information Architecture) dan Al3 (Acquire and Maintain Technology Infrastructure).

\subsection{Wawancara dan Kuesioner}

Setelah mendapatkan fokus domain penelitian maka akan dilakukan dilakukan proses wawancara dan kuesioner. Proses wawancara tidak hanya dilakukan untuk menentukan permasalahan awal saja namun proses ini juga diperlukan untuk menyesuaikan kebutuhan perusahaan terhadap layanan infrastruktur jaringan teknologi informasi menurut pemangku kepentingan yang ada di RSUD Provinsi NTB. Untuk mendapatkan nilai valid dari penelitian diperlukan adanya kuesioner. Kuesioner yang diberikan berupa pertanyaan tentang 6 atribut kematangan COBIT.

Penentuan responden proses wawancara dan kuesioner pada tahap ini berdasarkan RACl chart yang telah ditetapkan berdasarkan fokus domain PO2 dan Al3.

\subsection{Uji Reliabilitas dan Validitas}

Mengukur nilai reliabilitas dilakukan untuk menunjukkan dan memastikan adanya keseragaman nilai alat pengukur dalam suatu penelitian. Dengan menggunakan metode Cronbach's Alpha, data variabel penelitian dapat dinyatakan memiliki nilai reliabel apabila nilai Alpha yang didapatkan lebih besar dari 0.6. Metode ini akan menghasilkan nilai Alpha antara 0 sampai 1.

Proses pengujian alat pengumpul data dilakukan untuk memastikan bahwa alat tersebut mencerminkan indikator variabel yang diteliti. Proses ini disebut dengan Uji Validitas, dalam uji validitas pada penelitian ini menggunakan metode Korelasi Pearson. Nilai Korelasi Pearson didapatkan dengan mengkorelasikan skor butir pada kuisioner dengan skor totalnya.

\subsection{Identifikasi Maturity Level}

Pada tahap ini dilakukan identifikasi maturity level terhadap IT Proses terpilih yakni PO2 dan AI3. Tujuan dari tahapan ini adalah untuk mengetahui di mana posisi RSUD Provinsi NTB saat ini dan posisi yang diharapkan. Nilai maturity level didapat dengan mencari rata-rata jawaban pada masing-masing atribut, selanjutnya akan dilakukan pembobotan terhadap hasil rata-rata tersebut.

\subsection{Rekomendasi Perbaikan}

Dari hasil pengukuran maturity model yang didapat maka dibuatlah suatu rekomendasi perbaikan. Tahapan ini akan memberikan sebuah rekomendasi perbaikan yang memungkinkan layanan infrastruktur jaringan teknologi informasi di RSUD Provinsi NTB berada di tingkat yang lebih tinggi dari sebelumnya. Rekomendasi ini berupa penjabaran beberapa tindakan yang perlu dilakukan agar nilai maturity masing-masing atribut mencapai nilai maturity yang diharapkan. 


\section{Hasil dan Pembahasan}

\subsection{Rekapitulasi Responden Wawancara dan Kuesioner}

Berdasarkan RACl chart IT Proses PO2 terdapat sejumlah 13 orang responden dan IT Proses AI3 terdapat sejumlah 12 orang responden. Pemilihan responden ini berdasarkan aktifitas-aktifitas terkait $\mathrm{TI}$ yang ada di RSUD Provinsi NTB.

\subsection{Uji Reliabilitas dan Uji Validitas}

\subsubsection{Interquartile range}

Berdasarkan hasil rekapitulasi kuesioner yang telah dilakukan maka tahap selanjutnya ada menghitung nilai IQR. Untuk memudahkan pembaca dalam memahami nilai IQR maka akan direpresentasikan dalam bentuk Boxplot. Boxplot IT Proses PO2 dapat dilihat pada Gambar 2 dan Boxplot IT Proses AI3 dapat dilihat pada Gambar 3.

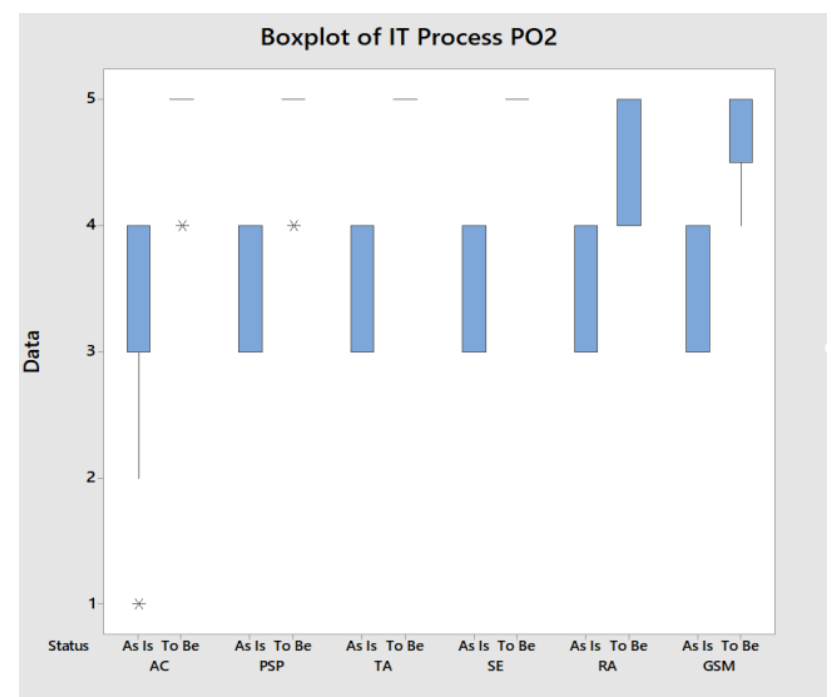

Gambar 2. Boxplot IT Proses PO2

Gambar 2 merupakan representasi dari nilai IQR dari IT Proses PO2. Pada atribut AC kondisi Saat ini terdapat tanda bintang (*) satu yang menunjukkan bahwa terdapat nilai outlier sebanyak satu pada data dengan nilai 1 . Nilai IQR IT Proses PO2 dapat dilihat berdasarkan panjangnya diagram batang berwarna biru, contohnya pada atribut AC kondisi Saat ini memiliki nilai IQR 1. Nilai IQR atribut AC pada kondisi saat ini didapatkan dari panjangnya data dari nilai 3 ke 4 yakni 1 , nilai minimum atribut $A C$ adalah 1 dan nilai maksimum atribut $A C$ adalah 4 . Contoh selanjutnya adalah atribut GSM pada kondisi yang diharapkan memiliki nilai IQR 0.5 dengan nilai minimum 4 dan nilai maksimum 5.

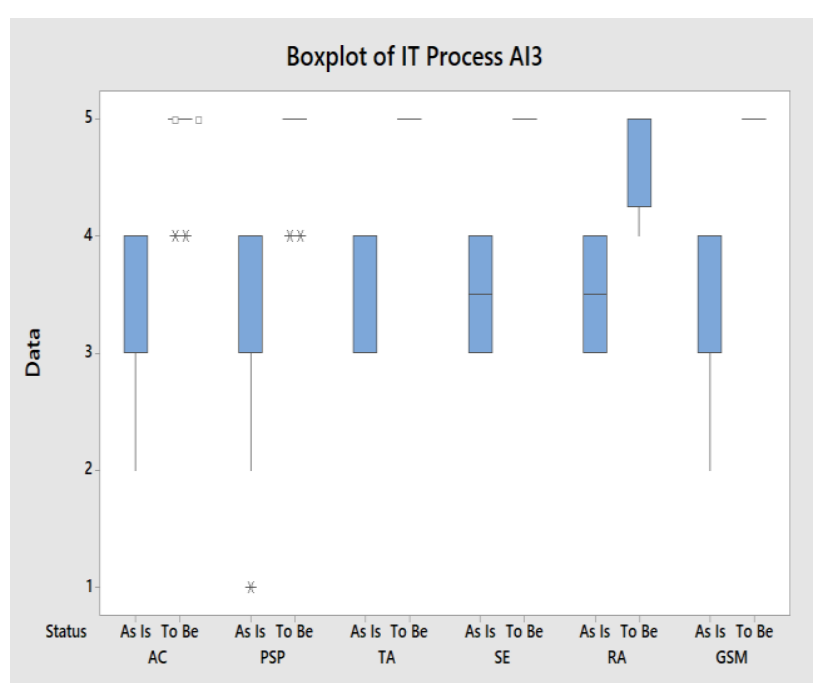

Gambar 3. Boxplot IT Proses AI3

Gambar 3 merupakan representasi dari nilai IQR dari IT Proses AI3. Pada atribut AC kondisi Yang diharapkan terdapat tanda bintang $\left({ }^{* *}\right)$ dua yang menunjukkan bahwa terdapat nilai outlier sebanyak dua pada data dengan nilai 4. Nilai IQR untuk atribut AC kondisi To Be bernilai 0 karena tidak muncul diagram batang berwarna biru dengan nilai minimum 4 dan nilai maksimum 5. Sebagai contoh lainnya, pada atribut PSP dengan kondisi Saat ini memiliki nilai IQR 1 didapatkan dari panjangnya data dari nilai 3 ke 4 yakni 1, nilai minimum atribut PSP adalah 1 dan nilai maksimum atribut PSP adalah 4.

\subsubsection{Uji reliabilitas cronbaach's alpha}

Hasil perhitungan uji reliabilitas dengan metode Cronbach's Alpha dari kedua IT Proses PO2 dan AI3 dapat dilihat pada Tabel I sebagai berikut.

TABEL I. HASIL UJI RELIABILITAS

\begin{tabular}{|c|c|c|c|}
\hline IT Proses & Status & Nilai & Reliabilitas \\
\hline \multirow{2}{*}{ PO2 } & Saat ini & 0.78 & Reliabel \\
\cline { 2 - 4 } & $\begin{array}{c}\text { Yang } \\
\text { diharapkan }\end{array}$ & 0.78 & Reliabel \\
\hline \multirow{2}{*}{ Al3 } & \begin{tabular}{c} 
Saat ini \\
Yang \\
\cline { 2 - 4 }
\end{tabular} & 0.79 & Reliabel \\
\hline
\end{tabular}

\subsubsection{Uji validitas korelasi pearson}

Hasil perhitungan uji validitas menggunakan metode Korelasi Pearson dari kedua IT Proses PO2 dan Al3 dapat dilihat pada Tabel II dan Tabel III sebagai berikut. 
TABEL II. HASIL UJI VALIDITAS PO2

\begin{tabular}{|c|c|c|c|c|}
\hline $\begin{array}{l}\text { Atrib } \\
\text { ut }\end{array}$ & Status & $\begin{array}{l}r- \\
\text { hitun } \\
g \\
\end{array}$ & $\begin{array}{l}r- \\
\text { tabel}(N= \\
13)\end{array}$ & $\begin{array}{l}\text { Validit } \\
\text { as }\end{array}$ \\
\hline \multirow[b]{2}{*}{$A C$} & Saat ini & 0.804 & 0.553 & Valid \\
\hline & $\begin{array}{l}\text { Yang } \\
\text { diharapkan }\end{array}$ & 0.841 & 0.553 & Valid \\
\hline \multirow[b]{2}{*}{ PSP } & Saat ini & 0.659 & 0.553 & Valid \\
\hline & $\begin{array}{l}\text { Yang } \\
\text { diharapkan }\end{array}$ & 0.841 & 0.553 & Valid \\
\hline \multirow[b]{2}{*}{ TA } & Saat ini & 0.659 & 0.553 & Valid \\
\hline & $\begin{array}{l}\text { Yang } \\
\text { diharapkan }\end{array}$ & - & 0.553 & Valid \\
\hline \multirow[b]{2}{*}{ SE } & Saat ini & 0.555 & 0.553 & Valid \\
\hline & $\begin{array}{l}\text { Yang } \\
\text { diharapkan }\end{array}$ & - & 0.553 & Valid \\
\hline \multirow[b]{2}{*}{ RA } & Saat ini & 0.879 & 0.553 & Valid \\
\hline & $\begin{array}{l}\text { Yang } \\
\text { diharapkan }\end{array}$ & 0.768 & 0.553 & Valid \\
\hline \multirow[b]{2}{*}{ GSM } & Saat ini & 0.704 & 0.553 & Valid \\
\hline & $\begin{array}{l}\text { Yang } \\
\text { diharapkan }\end{array}$ & 0.791 & 0.553 & Valid \\
\hline
\end{tabular}

TABEL III. HASIL UJI VALIDITAS AI3

\begin{tabular}{|l|l|l|l|l|}
\hline \multirow{2}{*}{$\begin{array}{l}\text { Atrib } \\
\text { ut }\end{array}$} & Status & $\begin{array}{l}\mathbf{r}- \\
\text { hitun } \\
\mathbf{g}\end{array}$ & $\begin{array}{l}\text { r- } \\
\text { tabel(N=1 } \\
\mathbf{2})\end{array}$ & $\begin{array}{l}\text { Validit } \\
\text { as }\end{array}$ \\
\hline \multirow{4}{*}{ AC } & Saat ini & 0.837 & 0.576 & Valid \\
\cline { 2 - 5 } & $\begin{array}{l}\text { Yang } \\
\text { diharapkan }\end{array}$ & 0.878 & 0.576 & Valid \\
\hline \multirow{3}{*}{ PSP } & Saat ini & 0.759 & 0.576 & Valid \\
\cline { 2 - 5 } & $\begin{array}{l}\text { Yang } \\
\text { diharapkan }\end{array}$ & 0.878 & 0.576 & Valid \\
\hline \multirow{3}{*}{ TA } & Saat ini & 0.668 & 0.576 & Valid \\
\cline { 2 - 5 } & $\begin{array}{l}\text { Yang } \\
\text { diharapkan }\end{array}$ & - & 0.576 & Valid \\
\hline \multirow{3}{*}{ SE } & Saat ini & 0.610 & 0.576 & Valid \\
\cline { 2 - 5 } & $\begin{array}{l}\text { Yang } \\
\text { diharapkan }\end{array}$ & - & 0.576 & Valid \\
\hline \multirow{2}{*}{ RA } & Saat ini & 0.610 & 0.576 & Valid \\
\cline { 2 - 5 } & $\begin{array}{l}\text { Yang } \\
\text { diharapkan }\end{array}$ & 0.630 & 0.576 & Valid \\
\hline \multirow{2}{*}{ GSM } & Saat ini & 0.770 & 0.576 & Valid \\
\cline { 2 - 5 } & $\begin{array}{l}\text { Yang } \\
\text { diharapkan }\end{array}$ & - & 0.576 & Valid \\
\hline
\end{tabular}

\subsection{Perhitungan Maturity Level}

Perhitungan nilai maturity level dari IT proses $\mathrm{PO} 2$ dan proses Al3 dengan masing-masing proses memiliki dua kondisi dan 6 atribut pertanyaan pada masingmasing kondisi. Setelah semua bobot maturity level dari masing-masing atribut didapatkan maka bobot tersebut akan dibulatkan. Sistem pembulatan yang dilakukan adalah dengan memperhatikan nilai dibelakang koma, jika lebih dari 0.5 maka akan dibulatkan ke atas dan jika kurang maka akan dibulatkan ke bawah. Nilai pembulatan ini juga melihat dari kondisi saat ini dan harapan yang diinginkan oleh pihak manajemen di RSUD Provinsi NTB berdasarkan proses wawancara dan kuesioner. Nilai pembulatan maturity level ini dapat dilihat pada Tabel IV dan Tabel V.

TABEL IV. MATURITY LEVEL PO2

\begin{tabular}{|l|l|l|l|l|l|}
\hline \multirow{2}{*}{$\begin{array}{l}\text { N } \\
\text { o }\end{array}$} & \multirow{2}{*}{$\begin{array}{l}\text { Atrib } \\
\text { ut }\end{array}$} & \multicolumn{2}{|c|}{ Kondisi Saat ini } & \multicolumn{2}{c|}{$\begin{array}{l}\text { Kondisi Yang } \\
\text { diharapkan }\end{array}$} \\
\cline { 3 - 6 } & $\begin{array}{l}\text { Nilai } \\
\text { ty }\end{array}$ & $\begin{array}{l}\text { Maturi } \\
\text { ty level }\end{array}$ & $\begin{array}{l}\text { Nilai } \\
\text { Maturi } \\
\text { ty }\end{array}$ & $\begin{array}{l}\text { Maturi } \\
\text { ty level }\end{array}$ \\
\hline 1 & AC & 3.23 & 3 & 4.92 & 5 \\
\hline 2 & PSP & 3.69 & 4 & 4.92 & 5 \\
\hline 3 & TA & 3.69 & 4 & 5 & 5 \\
\hline 4 & SE & 3.38 & 3 & 5 & 5 \\
\hline 5 & RA & 3.38 & 3 & 4.69 & 5 \\
\hline 6 & GSM & 3.46 & 3 & 4.77 & 5 \\
\hline
\end{tabular}

TABEL V. MATURITY LEVEL AI3

\begin{tabular}{|l|l|l|l|l|l|}
\hline \multirow{2}{*}{$\begin{array}{l}\text { N } \\
\text { o }\end{array}$} & \multirow{2}{*}{$\begin{array}{l}\text { Atrib } \\
\text { ut }\end{array}$} & \multicolumn{2}{|c|}{ Kondisi Saat ini } & \multicolumn{2}{|c|}{$\begin{array}{l}\text { Kondisi Yang } \\
\text { diharapkan }\end{array}$} \\
\cline { 3 - 6 } & $\begin{array}{l}\text { Nilai } \\
\text { Maturi } \\
\text { ty }\end{array}$ & $\begin{array}{l}\text { Maturi } \\
\text { ty level }\end{array}$ & $\begin{array}{l}\text { Nilai } \\
\text { Maturi } \\
\text { ty }\end{array}$ & $\begin{array}{l}\text { Maturi } \\
\text { ty level }\end{array}$ \\
\hline 1 & AC & 3.42 & 3 & 4.83 & 5 \\
\hline 2 & PSP & 2.83 & 3 & 4.83 & 5 \\
\hline 3 & TA & 3.67 & 4 & 5 & 5 \\
\hline 4 & SE & 3.5 & 3 & 5 & 5 \\
\hline 5 & RA & 3.5 & 3 & 4.75 & 5 \\
\hline 6 & GSM & 3.5 & 3 & 5 & 5 \\
\hline
\end{tabular}

Untuk merepresentasikan nilai dari maturity level tiap-tiap atribut maka dibuatlah dalam bentuk grafik. Grafik yang digunakan dalam merepresentasikan nilai maturity level pada penelitian ini adalah Spider Chart untuk memudahkan pembaca dalam memahami kondisi saat ini dari RSUD Provinsi NTB dan kondisi yang diharapkan dari pihak manajemen. Berikut adalah Spider Chart kedua IT Proses PO2 dan AI3 secara berturut-turut yakni pada Gambar 3 dan Gambar 4. 


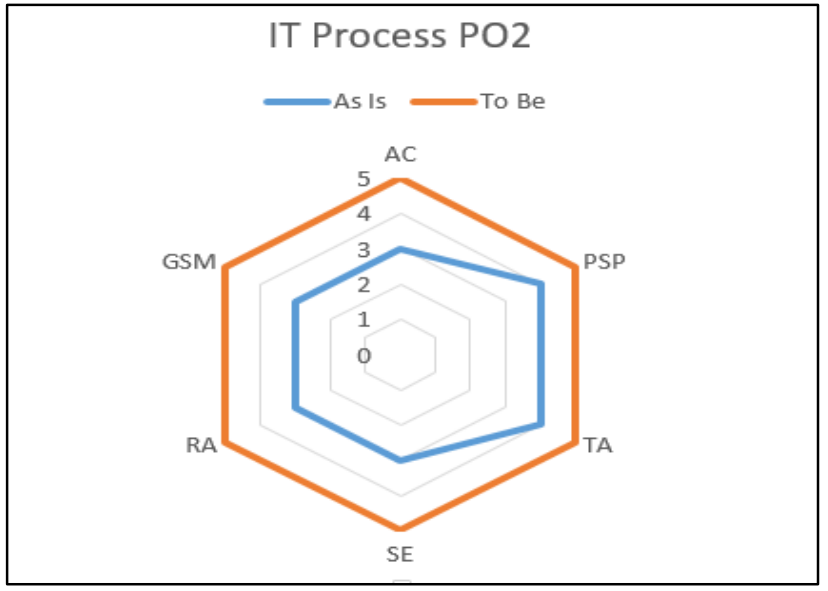

Gambar 3. Spider Chart IT Proses PO2

Gambar 3 merupakan represntasi dari nilai maturity level IT Proses PO2. Garis berwarna biru merepresentasikan kondisi saat ini dan garis berwarna merah merepresentasikan kondisi yang diharapkan. Pada kondisi saat ini untuk atribut AC, SE, RA dan GSM berada pada jaring dengan nilai 3 yang berarti bahwa nilai maturity pada kondisi saat ini secara umum berada pada level 3 sedangkan untuk atribut PSP dan TA berada pada jaring dengan nilai 4 yang berarti bahwa nilai maturity pada kondisi saat ini berada pada level 4. Pada kondisi yang diharapkan untuk atribut $A C$, PSP, TA, SE, RA dan GSM berada pada jaring dengan nilai 5 yang berarti bahwa nilai maturity yang diharapkan berada pada level 5 .

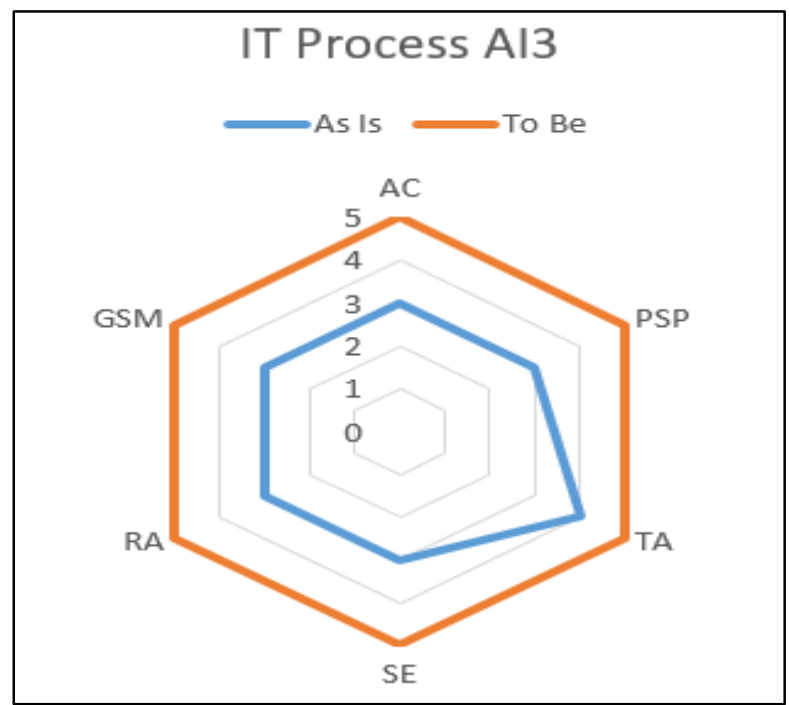

Gambar 4. Spider Chart IT Proses AI3

Gambar 4 merupakan representasi dari nilai maturity level IT Proses AI3. Garis berwarna biru merepresentasikan kondisi saat ini dan garis berwarna merah merepresentasikan kondisi yang diharapkan. Pada kondisi Saat ini untuk atribut AC, PSP, SE, RA dan GSM berada pada jaring dengan nilai 3 yang berarti bahwa nilai maturity pada kondisi saat ini berada pada level 3 sedangkan untuk atribut TA berada pada jaring dengan nilai 4 yang berarti bahwa nilai maturity pada kondisi saat ini berada pada level 4. Pada kondisi yang diharapkan untuk atribut AC, PSP, TA, SE, RA dan GSM berada pada jaring dengan nilai 5 yang berarti bahwa nilai maturity yang diharapkan berada pada level 5 .

\subsubsection{Analisis kondisi saat ini}

Nilai maturity level pada masing-masing atribut IT Proses PO2 dan Al3 secara umum menunjukkan level 3, namun pada atribut PSP dan atribut TA pada IT Proses PO2 nilai maturity menunjukkan nilai pada level 4 begitu pula pada atribut TA pada IT Proses AI3 menunjukkan nilai pada level 4.

Pada atribut Awareness and Communication (AC) dapat disimpulkan bahwa pihak manajemen RSUD Provinsi NTB saat ini telah memiliki pemahaman akan kebutuhan dalam mengembangkan sebuah arsitektur informasi melakukan perencanaan, implementasi dan pemeliharaan infrastruktur jaringan teknologi informasi serta telah ada komunikasi formal dan terstruktur dalam mengembangkan sebuah arsitektur informasi.

Pada atribut Policies, Standards and Procedures (PSP) dapat disimpulkan bahwa RSUD Provinsi NTB saat ini telah memahami pentingnya implementasi kebijakan, standar dan prosedur tentang perlindungan dan pengawasan infrastruktur jaringan teknologi informasi serta pengamanan dalam mengontrol akses kepemilikan data dan informasi.

Pada atribut Tools and Automation (TA) dapat disimpulkan bahwa RSUD provinsi NTB saat ini telah memiliki beberapa perangkat dalam upaya untuk mengembangkan arsitektur informasi dan beberapa perangkat infrastruktur jaringan yang telah terintegrasi.

Pada atribut Skill and Expertise (SE) dapat disimpulkan bahwa pengembangan keterampilan dan keahlian SDM yang dimiliki oleh RSUD Provinsi NTB saat ini telah didefinisikan sebuah rencana pelatihan formal dari pihak manajemen, namun saat ini untuk pelatihan SDM untuk mengembangkan keterampilan dan keahlian secara formal belum diadakan secara resmi oleh pihak manajemen.

Pada atribut Responsibility and Accountable (RA) dapat disimpulkan bahwa pihak manajemen di RSUD Provinsi NTB telah membagi tanggung jawab dan akuntabilitas tentang pengawasan pengembangan arsitektur informasi dan pengawasan terhadap implementasi infrastruktur jaringan.

Pada atribut Goal Setting and Measurment (GSM) dapat disimpulkan bahwa tujuan dari pengembangan 
arsitektur informasi dan implementasi infrastruktur jaringan di RSUD Provinsi NTB dapat menunjang tujuan bisnis.

\subsubsection{Analisis kondisi yang diharapkan}

Berdasarkan hasil wawancara dan kuesioner yang telah diberikan terhadap semua responden berdasarkan RACl chart yang telah ditentukan sebelumnya dapat disimpulkan bahwa pihak manajemen menginginkan semua atribut pada IT Proses PO2 dan Al3 berada pada maturity level 5 yaitu optimized.

Pada atribut Awareness and Communication (AC) dapat disimpulkan bahwa pihak manajemen di RSUD Provinsi NTB mengharapkan adanya pemahaman yang lengkap, maju dan visioner dalam mengimplementasikan dan memelihara infrastruktur jaringan teknologi serta mengembangkan arsitektur informasi.

Pada atribut Policies, Standards and Procedures (PSP), dapat disimpulkan bahwa pihak manajemen RSUD Provinsi NTB mengharapkan adanya kebijakan, standar dan prosedur tentang perlindungan dan pengawasan infrastruktur jaringan serta pengamanan dalam mengontrol akses kepemilikan data dan informasi yang diterapkan secara terbaik dan terintegrasi.

Pada atribut Tools and Automation (TA) dapat disimpulkan bahwa pihak manajemen RSUD Provinsi NTB mengharapkan adanya perangkat lengkap yang digunakan sepenuhnya dan terintegrasi dengan alatalat terkait sehingga mampu menciptakan arsitektur informasi yang optimal di RSUD Provinsi NTB.

Pada atribut Skill and Expertise (SE) dapat disimpulkan bahwa pihak manajemen RSUD Provinsi NTB mengharapkan adanya pengembangan keterampilan dan keahlian SDM yang diperlukan untuk memelihara infrastruktur jaringan, mengembangkan dan mempertahankan arsitektur informasi yang dimiliki oleh RSUD Provinsi NTB.

Pada atribut Responsibility and Accountable (RA) dapat disimpulkan bahwa pihak manajeman di RSUD Provinsi NTB mengharapkan adanya penerimaan tanggung jawab tentang pengawasan infrastruktur jaringan dan pengembangan arsitektur informasi telah diturunkan ke organisasi secara konsisten.

Pada atribut Goal Setting and Measurment (GSM) dapat disimpulkan bahwa RSUD Provinsi NTB mengharapkan adanya sistem pengukuran kinerja dari implementasi infrastruktur jaringan dan pengembangan arsitektur informasi yang dapat menunjang tujuan bisnis dari RSUD Provinsi NTB dan dilakukan perbaikan secara berkesinambungan.

\subsubsection{Analisis gap}

Berdasarkan hasil analisis nilai maturity level kondisi saat ini dan maturity level kondisi yang diharapkan maka didapatkan adanya gap nilai maturity level. Gap maturity level pada IT Proses PO2 besarnya adalah 2 tingkat pada atribut AC, SE, RA, dan GSM yaitu dari maturity level 3 menuju ke nilai maturity level 5 , pada atribut PSP dan TA memiliki gap sebesar 1 tingkatan dimana nilai maturity level 4 menuju ke nilai maturity level 5.

\subsection{Rekomendasi Perbaikan}

Berdasarkan nilai-nilai maturity level yang telah didapatkan maka rekomendasi tindakan perbaikan dikelompokkan menjadi dua bagian yakni Pencapaian Maturity Level 4 dan Pencapaian Maturity Level 5. Dalam melaksanakan peningkatan maturity level dimulai dari atribut dengan nilai maturity level paling rendah agar diperoleh keseragaman nilai sehingga diharapkan proses peningkatan maturity level menjadi lebih efektif.

\subsubsection{Pencapaian maturity level 4}

Beberapa tindakan perbaikan yang perlu dilakukan agar nilai maturity level pada atribut AC, SE, RA dan GSM pada IT Proses PO2 dapat mencapai nilai maturity level 4 adalah sebagai berikut:

a. Pada atribut AC melakukan sosialisasi terhadap pentingnya memahami kebutuhan proses pengembangan arsitektur informasi, melakukan pendataan kebutuhan lalu menuangkannya ke dalam bentuk formal seperti nota dinas dan lainlain.

b. Pada atribut SE melakukan pelatihan formal kepada staf divisi software dan hardware SIRS secara berkala dan menumbuhkan rasa kerja sama antar staf serta melakukan rekruitasi pegawai ahli.

c. Pada atribut RA mendefinisikan tanggung jawab dan akuntabilitas secara jelas dan memberikan reward kepada pegawai.

d. Pada atribut GSM mencatat penyimpangan yang terjadi, melakukan perbaikan secara berkesinambungan dan mengukur efektifitas dan efisiensi pemanfaatan TI.

Beberapa tindakan perbaikan yang perlu dilakukan agar nilai maturity level pada atribut AC,PSP SE, RA dan GSM pada IT Proses AI3 dapat mencapai nilai maturity level 4 adalah sebagai berikut:

a. Pada atribut AC seperti melakukan sosialisasi terhadap pentingnya memahami kebutuhan untuk melakukan perencanaan, implementasi dan pemeliharaan infrastruktur jaringan teknologi informasi, melakukan pendataan kebutuhan lalu 
menuangkannya ke dalam bentuk formal seperti nota dinas dan lain-lain.

b. Pada atribut PSP membuat kebijakan, standar dan prosedur dari perencanaan, implementasi dan pemeliharaan infrastruktur jaringan teknologi informasi kemudian memastikan bahwa implementasi dari kebijakan, standar dan prosedur tersebut telah diterapkan, disetujui, dan ditanda tangani oleh pihak manajemen.

c. Pada atribut SE melakukan pelatihan formal kepada staf divisi hardware SIRS secara berkala dan menumbuhkan rasa kerja sama antar staf serta melakukan rekruitasi pegawai ahli.

d. Pada atribut RA mendefinisikan tanggung jawab dan akuntabilitas secara jelas dan memberikan reward kepada pegawai.

e. Pada atribut GSM menyediakan perangkat pendukung yang dapat digunakan untuk mengukur tingkat efisiensi dan efektifitas, mencatat penyimpangan yang terjadi dan melakukan perbaikan secara berkesinambungan.

\subsubsection{Pencapaian maturity level 5}

Beberapa tindakan perbaikan yang perlu dilakukan agar nilai maturity level pada atribut AC, PSP, TA SE, RA dan GSM pada IT Proses PO 2 dapat mencapai nilai maturity level 5 adalah sebagai berikut:

a. Pada atribut AC, memastikan bahwa pihak manajemen telah memiliki pemahaman yang lengkap, maju dan visioner mengenai kebutuhan arsitektur informasi dan melakukan komunikasi yang proaktif mengenai permasalahan yang muncul dari arsitektur informasi

b. Pada atribut PSP, melakukan pemantauan dari implementasi kebijakan, standar dan prosedur telah dijalankan dengan baik oleh seluruh pihak terkait yang berhubungan dengan arsitektur informasi kemudian melakukan dokumentasi secara berkesinambungan

c. Pada atribut TA melakukan penambahan router, kabel LAN dan bandwith internet, menganggarkan laptop dan komputer dengan spesifikasi lebih tinggi dan melakukan deteksi terhadap penyimpangan yang mungkin terjadi dari arsitektur informasi

d. Pada atribut SE, melakukan pelatihan untuk meningkatkan keterampilan dan keahlian para staf SIRS, menganggarkan dan menjadwalkan untuk ujian sertifikasi MCSE dan MCSD, dan menjadikan Knowledge Sharing sebagai budaya

e. Pada atribut RA, memastikan bahwa pihak manajemen terkait pengembangan arsitektur informasi telah diberdayakan untuk membuat keputusan dan mengambil tindakan, memastikan bahwa pihak manajemen telah menerima tanggung jawab dan akuntabilitas sesuai dengan perannya masing-masing tentang pengawasan dari pengembangan arsitektur informasi kemudian melakukan dokumentasi terhadap segala kegiatan.

f. Pada atribut GSM, memastikan bahwa perangkatperangkat pendukung untuk pengukuran kinerja dari arsitektur informasi yang telah dimiliki digunakan dengan optimal, menjadikan perbaikan arsitektur informasi secara berkesinambung sebagai "way of life" dan membuat Disaster Recovery Planning dan Business Continuity Planning sebagai perencanaan dalam menangani permasalahan $\mathrm{TI}$ yang akan mendatang.

Beberapa tindakan perbaikan yang perlu dilakukan agar nilai maturity level pada atribut AC, PSP, TA, SE, RA dan GSM pada IT Proses AI3 dapat mencapai nilai maturity level 5 adalah sebagai berikut:

a. Pada atribut AC, memastikan bahwa pihak manajemen telah memiliki pemahaman yang lengkap, maju dan visioner mengenai kebutuhan perencanaan, implementasi dan pemeliharaan infrastruktur jaringan teknologi informasi dan melakukan komunikasi yang proaktif mengenai permasalahan yang muncul dari perencanaan, implementasi dan pemeliharaan infrastruktur jaringan teknologi informasi

b. Pada atribut PSP, melakukan pemantauan dari implementasi kebijakan, standar dan prosedur telah dijalankan dengan baik oleh seluruh pihak terkait yang berhubungan dengan infrastruktur jaringan, membuat SOP perlindungan dan pengawasan infrastruktur kemudia melakukan dokumentasi.

c. Pada atribut TA, melakukan deteksi terhadap penyimpangan yang mungkin terjadi dari infrastruktur jaringan teknologi informasi yang ada di RSUD Provinsi NTB seperti melakukan Vulnerability Mapping dan melakukan perbaikan secara terus menerus terhadap penyimpangan yang terjadi, membuat jadwal pemeliharaan infrastruktur jaringan secara berkala dalam 6 bulan sekali dan menyediakan ruang penyimpanan perangkat-perangkat yang lebih luas dan disusun secara rapi.

d. Pada atribut SE, melakukan pelatihan untuk meningkatkan keterampilan dan keahlian para staf khususnya pada divisi hardware SIRS RSUD Provinsi NTB dalam memelihara infrastruktur jaringan teknologi informasi, menganggarkan dan menjadwalkan ujian sertifikasi CCENT, CCNA dan 
CCDA dan menjadikan Knowledge Sharing sebagai budaya.

e. Pada atribut RA, memastikan bahwa pihak manajemen terkait perencanaan, implementasi dan pemeliharaan infrastruktur jaringan teknologi informasi telah diberdayakan untuk membuat keputusan dan mengambil tindakan, memastikan bahwa pihak manajemen telah menerima tanggung jawab dan akuntabilitas sesuai dengan perannya masing-masing tentang perencanaan, implementasi dan pemeliharaan infrastruktur jaringan teknologi informasi kemudian melakukan dokumentasi terhadap segala kegiatan

f. Pada atribut GSM, memastikan bahwa perangkatperangkat pendukung untuk pengukuran kinerja infrastruktur jaringan yang telah dimiliki digunakan dengan optimal, menjadikan perbaikan infrastruktur jaringan teknologi informasi secara berkesinambung sebagai "way of life" dan membuat Disaster Recovery Planning dan Business Continuity Planning sebagai perencanaan dalam menangani permasalahan TI yang akan mendatang.

\subsubsection{Rencana aksi}

Rencana aksi diperlukan untuk mencapai goals atau tujuan-tujuan secara lebih efektif. Berikut adalah penjabaran lebih lanjut rencana-rencana aksi yang harus dilakukan:

1. Mengoptimalkan infrastruktur, sumber daya dan kapabilitas TI.

a. Menyediakan pembangunan dan uji lingkungan infrastruktur $\mathrm{TI}$, yaitu dilakukan dengan melakukan Wireless Penetration Testing untuk mengetahui tingkat kerentanan dari aplikasi-aplikasi yang dimiliki oleh RSUD Provinsi NTB; diperlukan juga ahli-ahli pada domain ini, untuk mendapatkan ahli pada bidang jaringan teknologi informasi dengan mengadakan ujian sertifikasi CCENT, CCNA dan CCDA kepada staf divisi hardware di RSUD Provinsi NTB.

b. Mengimplementasikan kontrol internal, keamanan dan langkah-langkah audit, yaitu dilakukan dengan menerapkan sistem manajemen identitas dan autentikasi; membuat suatu Disaster Recovery Planning yang menyediakan rencana untuk pemulihan layanan teknologi informasi setelah terjadi gangguan; dan membuat Business Continuity Planning yang menyediakan rencana untuk pengembalian operasi bisnis setelah terjadi gangguan; serta menerapkan Tata kelola
Teknologi Informasi sebagai langkah audit teknologi informasi di RSUD Provinsi NTB.

2. Akuisisi dan memelihara infrastruktur TI yang terintegrasi dan terstandarisasi.

a. Membuat suatu rencana akuisisi, yaitu dilakukan dengan mencatat setiap adanya perubahan dalam keadaan darurat terhadap perangkat infrastruktur. Setelah mengetahui adanya perubahan atau upgrade maka dapa dilakukan rekap terhadap infrastruktur TI yang dimiliki saat ini dan yang harus dimiliki pada waktu mendatang. Kemudian hasil akhirnya dapat membuat suatu rencana pengadaan infrastruktur $\mathrm{TI}$ yang selaras dengan kebutuhan dan rencana strategis RSUD Provinsi NTB.

b. Merencanakan pemeliharaan infrastruktur TI, yaitu dilakukan dengan membuat suatu perencanaan untuk melakukan pemeliharaan infrastruktur TI secara berkala. Melakukan pemeriksaan terhadap infrastrukturinfrastruktur TI yang sudah mengalami kerusakan atau yang akan mengalami kerusakan dan mencatatnya. Dalam melakukan pemeliharaan infrastruktur TI juga membutuhkan suatu ruangan khusus untuk menyimpan infrastruktur tidak terpakai dan terpakai secara terpisah.

3. Mengoptimalkan penggunaan informasi dapat diraih dengan cara:

a. Melakukan klasifikasi informasi, di mana setiap informasi akan diklasifikasikan berdasarkan skema yang telah dibuat dan disepakati oleh pihak manajemen. Klasifikasi informasi ini dibagi berdasarkan bidangbidang dan instalasi yang ada di RSUD Provinsi NTB. Data pasien dalam berbagai instalasi perawatan akan disimpan di dalam bagian Rekam Medis. SIRS secara khusus digunakan untuk pengolahan dan penyimpanan data keuangan.

b. Memelihara integritas data, dapat dilakukan dengan memastikan setiap data yang dimasukkan ke dalam SIRS oleh administrator dilakukan dengan teliti agar menjaga data yang dimasukkan berupa data yang valid. Untuk memelihara integritas data dapat dilakukan dengan memasukkan aturan bisnis yang telah sesuai SOP dari RSUD Provinsi NTB seperti biaya perawatan rawat jalan, rawat inap, melakukan penelitian dan lain sebagainya ke dalam SIRS khususnya pada 
data keuangan, sehingga meminimalisir terjadinya salah hitung dalam hal keuangan. Diperlukan adanya ujian sertifikasi seperti MCSE dan MCSD untuk memastikan bahwa staf divisi software Instalasi SIRS RSUD Provinsi memiliki keahlian dalam mengembangkan suatu Sistem Informasi.

4. Memastikan integrasi aplikasi dengan proses bisnis dapat diraih dengan cara:

a. Memastikan akurasi dari arsitektur informasi dan model data, di mana akurasi dari arsitektur informasi merupakan hal terpenting dalam implementasinya. Akurasi dari arsitektur informasi dapat meminimalisir terjadinya error saat implementasi. Dalam memastikan akurasi dari implementasi arsitektur informasi dapat dilakukan dengan melakukan Vulnerability Mapping dan menghitung jumlah pembaruan dari model data yang diterapkan, semakin berkembangnya kebutuhan maka model datanya pun akan berubah.

b. Menugaskan kepemilikan data, dapat dilakukan dengan cara menentukan pihakpihak yang berwenang dan memiliki kewajiban terhadap suatu proses TI. Di RSUD Provinsi NTB pihak yang berwenang sebagai pemilik data (data owner) dalam proses teknologi informasi adalah Instalasi SIRS yang berada pada divisi software. Namun di Instalasi SIRS hanya memiliki dua orang programmer yang meng-handle seluruh sistem informasi di RSUD Provinsi NTB. Diperlukan penambahan staf divisi software yang mumpuni dalam mengembangkan arsitektur informasi.

5. Menanggapi kebutuhan bisnis yang selaras dengan strategi bisnis dapat diraih dengan cara:

a. Memastikan konsistensi berdasarkan komponen infrastruktur TI, yaitu dengan membuat suatu arsitektur informasi yang handal dan memiliki aplikasi, kamus data, syntax data, skema klasifikasi serta level keamanan yang telah terdefinisi dan terstandar. Mencatat aplikasi yang sesuai dan tidak sesuai dengan kebutuhan bisnis RSUD Provinsi NTB dapat menjadi langkah meminimalisir aplikasi tidak terpakai.

\section{KeSIMPULAN DAN SARAN}

\subsection{Kesimpulan}

Berikut adalah beberapa kesimpulan yang dapat dipaparkan dari hasil penelitian tata kelola TI di RSUD Provinsi NTB:

1. Atribut $A C, S E, R A$ dan GSM pada IT Proses $P O 2$ dan atribut AC, PSP, SE, RA, GSM pada IT Proses AI3 saat ini berada pada maturity level 3 Defined Process (proses yang terdefinisi) yang berarti RSUD Provinsi NTB mulai menyadari adanya kebutuhan akan pentingnya layanan teknologi informasi. Sedangkan pada atribut PSP dan TA pada IT Proses PO2 dan pada atribut TA IT Proses AI3 berada pada maturity level 4 atau Managed and Measurable (dapat diatur dan diukur) yang berarti bahwa RSUD Provinsi NTB telah memahami pengelolaan layanan teknologi informasi diseluruh bagian dan didukung dengan melakukan pelatihan SDM SIRS secara formal dan berkala.

2. Berdasarkan hasil wawancara dan kuesioner untuk semua atribut pada IT Proses PO2 dan Al3 yang diharapkan berada pada maturity level 5 atau Optimised (optimal) yang berarti bahwa prosesproses di dalam RSUD Provinsi NTB telah berada ditahap yang optimal dan sempurna berdasarkan pada proses peningkatan yang dilakukan secara terus-menerus.

3. Untuk mencapai nilai maturity level yang optimal, rekomendasi perbaikan dituangkan ke dalam rencana aksi yang berisi penjabaran aktifitasaktifitas perbaikan yang harus dilakukan seperti mengoptimalkan penggunaan infrastruktur TI yang dapat ditempuh dengan melakukan Wireless Penetration Testing dan membuat arsitektur informasi yang handal.

\subsection{Saran}

Untuk menyempurnakan penelitain ini diperlukan beberapa saran. Berikut adalah beberapa saran berdasarkan hasil penelitian Tata Kelola Teknologi Informasi di RSUD Provinsi NTB:

1. Untuk dapat menerapkan Tata Kelola Teknologi Informasi seperti yang telah diuraikan, diharapkan pihak manajemen di RSUD Provinsi NTB untuk melakukan audit tata kelola teknologi informasi secara berkala seiring dengan perkembangan teknologi informasi yang akan datang.

2. Agar hasil tata kelola teknologi informasi lebih maksimal, diharapkan pihak manajemen melakukan tata kelola TI pada seluruh IT Proses yang terdapat pada framework COBIT 4.1 sehingga penerapan TI di RSUD Provinsi NTB dapat 
terintegrasi secara maksimal dan menunjang tujuan bisnisnya.

\section{UCAPAN TERIMA KASIH}

Pada kesempatan ini penulis menyampaikan ucapan terima kasih yang setulus-tulusnya kepada Bapak Direktur dan pihak manajemen RSUD Provinsi NTB selaku responden yang telah mengisi kuesioner sebagai bahan untuk proses analisis data sehingga dapat menjadi sebuah Tugas Akhir yang lengkap.

\section{DAFTAR PUSTAKA}

[1] K. Surendro, Implementasi Tata Kelola Teknologi Informasi, Bandung: Informatika, 2009.

[2] I. G. Institute, COBIT 4.1 Framework Control Objectives Management Guidelines, Maturity Models, USA: IT Governance Institute, 2007.

[3] A. Ansori and J. L. Buliali, PERANCANGAN TATA KELOLA JAMINAN KETERSEDIAAN LAYANAN TEKNOLOGI INFORMASI PADA RUMAH SAKIT UMUM DAERAH (RSUD) KABUPATEN SIDOARJO, Surabaya: Institut Teknologi Sepuluh Nopember, 2011.

[4] Z. S. Santi, Analisis Sistem Keamanan Jaringan Komputer Pada PT.MALINDO FEEDMILL TBK Menggunakan Framework COBIT 4.1 Pada Domain
DS5 (Ensure System Sequrity), Semarang: Universitas Dian Nuswantoro, 2014.

[5] R. Alit, I. D. Pratiwi and M. Idhom, "TIngkat Kematangan Infrastruktur Teknologi Informasi Pada Domain Acquire and Implement Menggunakan COBIT 4.1 (Studi Kasus: UPT Perpustakaan Universitas Pembangunan Nasional "Veteran" Jawa Timur)," KINETIK, vol. 2, no. 3, pp. 227-234, 2017.

[6] W. A. Nugroho, Analisis Kinerja Perusahaan Dengan Konsep Balanced Scorecard (Studi Kasus PT. Wijaya Karya), Jakarta: UIN Syarif Hidayatulllah, 2013.

[7] A. D. Nastiti, Perancangan Tata Kelola Teknologi (IT Governance) Dengan Menggunakan Metode COBIT 4.1 (Studi Kasus UIN SUSKA Riau), Riau: Universitsaat inilam Negeri Sultan Syarif Kasim, 2013.

[8] I. S. Rozas, Mengukur Efektifitas Hasil Audit Teknologi Informasi Cobit 4.1 berdasarkan Perspektif End User, Surabaya: Jurnal Sistem Informasi. Universitas Narotama, 2012.

[9] A. Suryadi, Peningkatan Tata Kelola Teknologi Informasi Pada Layanan Infrastruktur Jaringan Menggunakan Framework Cobit 4.1 Di SInergi Foundation, Garut: STKIP, 2016.

[10] W. T. Pamungkas, Pengembangan Struktur Jaringan Client-Server Kelurahan Bintaro, Jakarta: UIN Syarif Hidayatulah, 2013. 